\title{
Prevalence of Human Intestinal Helminth Parasites among Undergraduate Students at the off Campus (North Gate Area), Federal University of Technology, Akure (Futa), Nigeria
}

\author{
Ebenezer Oluyemi Dada1, Christiana Eleojo Aruwa ${ }^{2 *}$ \\ Department of Microbiology, Federal University of Technology, Akure, Nigeria \\ Email: "queen.eleojo29@gmail.com
}

Received 7 March 2015; accepted 22 March 2015; published 26 March 2015

Copyright (C) 2015 by authors and OALib.

This work is licensed under the Creative Commons Attribution International License (CC BY). http://creativecommons.org/licenses/by/4.0/

(c) (i) Open Access

\begin{abstract}
Studies have shown that soil-transmitted helminth infections are widely distributed throughout the tropics and subtropics. Poor sanitation is a major factor in the spread of intestinal helminth parasites. Hence, a study was carried out from July to September 2014, to determine the prevalence of intestinal helminth parasites among undergraduate students at North Gate, FUTA. A total of two hundred (200) stool samples were collected randomly from both males and females. Faecal samples were analyzed using the formol-ether sedimentation and concentration method. Parasites encountered by prevalence were Taenia spp. (13.5\%), Ascaris lumbricoides (6.5\%), Enterobius vermicularis (2\%), Strongyloides stercoralis (6\%), Trichuris trichiura (5\%), Schistosoma mansoni $(3.5 \%)$ and Hookworm species (8\%). Formol-ether concentration technique was used to analyze the stool samples. The overall infection rate was 89 (44.5\%). The study showed that infections were more prevalent among males. The highest prevalence of infections was recorded among the age group of $19-22$ years $(21 \%)$ in both sexes, and least infection rate in the age group of $27-30$ years $(1.0 \%)$. The highest prevalence of infection was observed with students who made use of pit latrine (22\%), compared with students who made use of bush system (7.5\%). Prevalence for users of water closet was $11 \%$. On the basis of the type of toilet system, the bucket system showed the least prevalence of $4 \%$. Prevalence of helminth parasite infection was the highest among students using pipe borne water (22\%) system as source of water, compared with users of stream/pond/ river water source, which had the least prevalence $(3.5 \%)$. The study showed that there was a need to encourage the practice of good personal hygiene and sanitation. The health implication of low level of hygiene and faecal pollution of the environment related to prevalence is discussed.
\end{abstract}

${ }^{*}$ Corresponding author.

How to cite this paper: Dada, E.O. and Aruwa, C.E. (2015) Prevalence of Human Intestinal Helminth Parasites among Undergraduate Students at the off Campus (North Gate Area), Federal University of Technology, Akure (Futa), Nigeria. Open Access Library Journal, 2: e1399. http://dx.doi.org/10.4236/oalib.1101399 


\title{
Keywords
}

\author{
Intestinal Helminths, Parasites, Stool, Prevalence, Infections, Health
}

\author{
Subject Areas: Microbiology
}

\section{Introduction}

Damage of intestinal helminth parasites to host cells becomes most evident, especially when the parasite burden becomes too high [1] [2]. Intestinal parasites may do harm to their host by absorbing food intended for the host [1]. There is enough evidence to show that blood or lymph could be sucked by parasites like hookworms [3]. Parasites like Ascaris feed on the tissue of the host causing wound through which infections may enter (ibid). It has been noted that intestinal parasitic infections are among the major public and socioeconomic concerns that have adversely affected the well-being of the poor in developing countries as they can lead morbidity and mortality [4]. Studies have shown that soil-transmitted helminth infections are widely distributed throughout the tropics and subtropics [5]. Climate is an important determinant of transmission of these infections, with adequate moisture and warm temperature essential for larval development in the soil [6]. It has been estimated that Ascaris lumbricoides, hookworm and Trichuris trichiura infect 1,450 million, 1,300 million and 1,050 million people worldwide, respectively, while schistosomiasis affects over 200 million people [5]. Globally, two billion individuals were infected with intestinal parasites; out of these majorities were children due to malnutrition [5]. Particularly in Sub-Saharan Africa, it was stipulated that parasitic infections were the major public health problem. Apart from causing morbidity and mortality, infections with intestinal parasites have been associated with stunting, physical weakness and low educational performance of schoolchildren [5]. It was stated that soil transmitted helminths are transmitted by eggs that are passed in the faeces of infected people [3] [6]. Adult worms live in the intestine where they produce thousands of eggs each day. This can happen in several ways: for instance when eggs that are attached to vegetables are ingested, when vegetables are not carefully cooked, washed or peeled; when eggs are ingested from contaminated water sources, and when eggs are ingested by children who play in soil, and then put their hands in their mouths without washing them. Also, hookworm eggs hatch in the soil, releasing larvae that mature into forms that can actively penetrate the skin. People become infected with hookworm primarily by walking barefoot on the contaminated soils [3].

In Nigeria, like any other developing countries, human intestinal parasitic infections are very common, especially among children that play on the ground bare footed, or those that eat contaminated foods and use contaminated water. These have been the major problems in rural settlements in Nigeria because of their poor socioeconomic status and lack of basic amenities, such as water and toilet facilities [7] [8]. In most cases, the intestinal helminths of major medical importance are Ascaris lumbricoides, Enterobius vermicularis, Strongyloides stercoralis, Trichuris trichiura, Ancylostoma duodenale, Necator americanus [9].

\section{Justification}

The Federal University of Technology, Akure (FUTA) area has 3 phases occupied by students, civil servants and the general public. During the course of this research, stool samples were collected from undergraduate students resident at north gate area of University. There is little or no information on the prevalence of intestinal parasites in this area, though less populated than the south gate area. Some of the people living in the area make use of wells and boreholes for domestic and industrial purposes. There are also few toilets. Some student residents make use of bushes around to defecate. Hence, this study attempts to determine the prevalence of intestinal helminth parasites, identify some risk factors, and determine which sex and age group are more prone to intestinal helminth parasitic infections in the North gate area of FUTA. This was aimed at providing initial data as bases for encouraging practice of good personal hygience and enforcement of sanitation practices.

\section{Methodology}

a) Sample collection and distribution of questionnaires 
Stool samples were collected from the students (both males and females) into sterile universal bottles. The sterile universal bottles were given to students every evening to produce early morning stool, and properly tightened to avoid contamination. A standard questionnaire was also distributed to obtain necessary information from the students on their age group, gender, and name of the lodge; sex, type of toilet facilities and source of water used. Stool samples collected were taken to the Microbiology laboratory for immediate analysis. Concentration techniques are useful for prevalence surveys to determine the eggs of intestinal helminths. The analysis was carried out by sedimentation technique using Formol-ether concentration methods [10]. Stool samples that were not examined the same day were preserved according to the method of Dada and Erinle [11]. Preservation of stool samples was done to avoid the stool from decaying by adding $4 \mathrm{ml}$ of formalineto each sample and stored in the refrigerator till the next day.

b) Analysis: sample sedimentation and concentration

The Formol-ether concentration method [12] was used to carry out the analysis in the laboratory. The advantage of the method is that it is quick and can be used to determine protozoan cysts also. About $2 \mathrm{~g}$ of faeces was emulsified in $7 \mathrm{ml}$ of $10 \%$ formalin in a centrifuge tube, using a swab stick. The mixture was passed through a sieve ( $0.75 \mathrm{~mm}$ pore size) into an evaporating basin. It was then placed in the centrifuge tube. $3 \mathrm{ml}$ of ether was added and shaken vigorously for at least $30 \mathrm{~s}$. The tube was then centrifuged at $3000 \mathrm{rpm}$ for 60 seconds. The fatty deposit at the interface of the liquids was loosened with a glass rod, and the centrifuge tube quickly inverted at an angle of $45^{\circ}$ to the ground so that the liquids runs out. A jet of water from a tap was run down the glass rod, while the debris is cleaned off from the tube with the rod. Some water ran up the space between rod and tube by capillary attraction and the deposit removed with a Pasteur pipette and examined on a microscope slide under the $\times 10$ objective [13].

c) Parasitological investigation for parasite eggs

After the spinning of the stool sample, the debris and supernatant were separated by decanting. Then, a Pasteur pipette was used to take $0.05 \mathrm{ml}$ of the sediment and mounted on a clean grease-free microscope slide, covered with a cover slip and viewed under $\times 10$ and $\times 40$ objective lens for the counting of the eggs of intestinal helminth parasites [10].

\section{Results}

The intestinal helminth parasites recorded from parasitological investigation include Taenia spp., Ascaris lumbricoides, Enterobius vermicularis, Strongyloides stercoralis, Trichuris trichiura, Schistosoma mansoni, Hookworms. Out of 200 samples examined microscopically, 89 were infected with one or more intestinal helminth parasites, while the remaining students were not infected. The overall prevalence of intestinal parasites were as follows: Taenia spp. 27 (13.5\%), Ascaris lumbricoides 13 (6.5\%), Enterobius vermicularis 4 (2.0\%), Strongyloides stercoralis 12 (6.0\%), Trichuris trichiura 10 (5.0\%), Schistosoma mansoni 7 (3.5\%), Hookworms 16 (8.0\%) respectively (Table 1 ). Table 2 showed the prevalence of infection based on the age group from males and females. All age groups were infected with different intestinal helminth parasites. There was highest infection rate was observed in the age group of 19 - 22 years (21\%), and least infection rate in the age group of 27 30 years $(1.0 \%)$.

Table 1. Overall prevalence of intestinal helminth infections among the students.

\begin{tabular}{ccc}
\hline Helminth parasites encountered & Number infected & Prevalence (\%) \\
\hline Strongyloides stercoralis & 12 & 6.0 \\
Taenia spp. & 27 & 13.5 \\
Enterobius vermicularis & 4 & 2.0 \\
Hookworm & 16 & 8.0 \\
Trichuris trichiura & 10 & 5.0 \\
Ascaris lumbricoides & 13 & 6.5 \\
Schistosoma mansoni & 7 & 3.5 \\
Total & 89 & 44.5 \\
\hline
\end{tabular}

$\mathrm{N}=200$ (total number of students examined). 
Table 3 showed the prevalence of infection based on toilet facilities used by the students. There highest prevalence of infection was observed with students who made use of pit latrine (22\%), followed by those students who made use of water closet (11\%), bush system (7.5\%), and the least prevalence with bucket system users (4\%). Table 4 showed the prevalence of infection based on the source of water used. The highest infection rate was recorded in those students that use pipe borne water (22\%), followed by those that make use of wells (19\%), followed by the least infection rate on those that made use of stream (3.5\%).

\section{Discussion}

Results from this study showed that there was high infection rate of human intestinal helminth parasites. The high prevalence of intestinal helminth parasite observed in this research might be due to poor sanitary disposal of faeces, inadequate water supply which was in line with Agwu [14] in Eastern part of Nigeria. Prevalence of intestinal helminthparasites; Taenia spp., Ascaris lumbricoides, Enterobius vermicularis, Strongyloides stercoralis, Trichuris trichiura, Schistosoma mansoni, and Hookworms are in line with Oninla et al. [15] who stated that these occurrence may be due to some risk factors such as poverty, poor habits of eating, level of education and low level of sanitary practices.

The occurrence and prevalence of Taenia spp. also could be related to the consumption of raw or improperly cooked meat (beef and pork) by the students who visit food vendors or eatery and poor animal management in the area by the Fulani. In the study estimated, the age group of 19 - 22 years was the most affected while the age group of 27 - 30 years was the least affected. This agrees with the submission of Willingham et al. [16] who opined that taeniasis mainly affect farming communities in impoverished regions of South-east Asia with poor water and sanitation, as well as poor animal management. Neurocysticercosis is a serious long-term sequel of Taenia solium infection and can substantially impede the well being of people.

Table 2. Prevalence of intestinal helminth parasites based on age group for both sexes.

\begin{tabular}{cccc}
\hline Age group & Number examined & Number infected & Prevalence (\%) \\
\hline $14-18$ years & 60 & 33 & 16.5 \\
$19-22$ years & 82 & 42 & 21 \\
$23-26$ years & 46 & 12 & 6 \\
27 - 30 years & 12 & 2 & 1 \\
Total & 200 & 89 & 44.5 \\
\hline
\end{tabular}

Table 3. Prevalence of infection based on toilet facilities (male and female).

\begin{tabular}{cccc}
\hline Toilet facilities & Number examined & Number infected & Prevalence (\%) \\
\hline Bucket & 15 & 8 & 4 \\
Bush system & 38 & 15 & 7.5 \\
Pit latrine & 105 & 44 & 22 \\
Water closet & 42 & 22 & 11 \\
Total & 200 & 89 & 44.5 \\
\hline
\end{tabular}

Table 4. Prevalence of helminth parasite infection based on the source of water.

\begin{tabular}{cccc}
\hline Source of water & Number examined & Number infected & Prevalence (\%) \\
\hline Wells & 57 & 38 & 19 \\
Stream/pond/River & 10 & 7 & 3.5 \\
Pipe borne water & 133 & 44 & 22 \\
Total & 200 & 89 & 44.5 \\
\hline
\end{tabular}


The occurrence of Ascaris lumbricoides in this study might be attributed to the unclean habits of eating without washing hands, poverty, and consumption of raw foods like vegetables and fruits commonly practiced among the students. This is in agreement with the findings of Chigozie et al. [4] who observed a high prevalence of Ascaris lumbricoides among the school children because of contamination of their hands with polluted soil, which often contain the infective eggs of the parasites, thereby enhancing transmission from hand to mouth. The prevalence of Ascaris lumbricoides and Trichuris trichiura in this study is low and it is in conformity with the findings in the study of Tedia and Ayele [17] where a low prevalence of ascariasis and trichuriasis among lowland dwellers was reported. Furthermore Tedia and Ayele [17] stated that the observed prevalence might be due to proper toilet facilities, proper hand washing habits and better awareness to health and sanitation. Reason for the high prevalence of hookworm spp. observed in this study could probably be due to the fact that the majority of students in the study area do play football barefooted on playgrounds that might have been contaminated with faecal matter. In 1995, Hotez and Pritchard [18] had earlier put forward that individuals who walk barefooted or with open footwear in faecal contaminated soil were at risk for hookworm infection.

The infection rate based on age group showed that there was high prevalence of these intestinal parasites among age group of 19 - 22 years and the least infection rate in those of the age group of 27 - 30 years respectively. This is in line with Luka et al. [9] who stated that pupils within the younger age groups often spend more of their leisure time outdoors, playing and foraging in garbage dumps and eating carelessly with unwashed hands. Also, the low prevalence observed in the age group of 27 - 30 years might be attributed to the fact that the students are more aware and enlightened on the need for good hygienic practice than the lower aged groups. Infection rate related to toilet facilities in this study revealed that students who make use of pit latrines had the highest prevalence compared to those who use bucket latrines, bush defecation sites and water closet toilets. This could be due to poor personal hygiene and usage of faecal contaminated soil and water in the area. This kind of finding is similar to the observations of Chigozie et al. [4] and Obiukwu et al. [19].

Furthermore, illiteracy, poverty in association with poor environmental sanitation practices have been implicated in the heavy burden of helminthiasis among children. Uwem et al. [20] observed in their study that the pit latrines of the school were so dirty that the pupils preferred to defecate in the surrounding bush close to public school compound. Sources of water used and prevalence of intestinal helminth parasites among the students revealed that prevalence was high among students who depended on pipe borne water than in those who depended on other sources of water for domestic chores. This might be due to leakages from the pipeline during distribution of water to the public. This agrees with the report of Agi [21] who conducted similar study in the Niger-Delta, and attributed this observation to the fact that water supplied in taps were not properly treated or contaminated before usage. This research work stressed the need for the State government to encourage and enforce good sanitation practice around the FUTA North gate area.

\section{Conclusion}

Intestinal helminth infections in people will remain a public health threat for as long as poverty persists in the developing countries. Morbidity and mortality attributable to intestinal helminth infections are on the increase with emergence and worldwide spread of the occurrence among the people, especially in children. As a consequence, there is a renewed interest in understanding the epidemiology, diagnosis and control of these infections. More importantly, deworming of students on regular basis could be carried out by public health workers, and vaccines should be made available on a large scale. Proper monitoring from public health authorities could also be emphasized. In addition, better and more effective laboratory diagnostic techniques should be developed. Inhabitants of various areas should be regularly educated on the importance of reducing the spread of infections. The provision of basic amenities such as regular electricity supply, pipe borne water, etc., would aid in reducing the occurrence of intestinal helminth parasites, and eradicating the diseases they cause. Practice of personal hygiene and good sanitation on daily basis as means of controlling or containing intestinal helminth infections cannot be overemphasized.

\section{References}

[1] Benesh, D.P. (2013) Parental Effects on the Larval Performance of a Tapeworm in Its Copepod First Host. Journal of Evolutionary Biology, 26, 1625-1633. http://dx.doi.org/10.1111/jeb.12165

[2] Christine, A.N. and Chistopher, S. (2000) Definition of a Parasite. British Medical Bulletin, 56, 193-208. 
http://dx.doi.org/10.1258/0007142001902897

[3] Raso, G., Luginbuhl, A. and Adjoua, C.A. (2004) Multiple Parasite Infections and Their Relationship to Self-Reported Morbidity in a Community of Rural Cote d'Ivoire. International Journal Epidemiology, 33, 1092-1102. http://dx.doi.org/10.1093/ije/dyh241

[4] Chigozie, J., Kelvin, O.E., Patrick, G.O., Nelsonm, C.A. and Emmanuel, A. (2007) Soil-Transmitted Helminth Infection in School Children in Eastern Nigeria: The Public Health Implication. Internet Journal of Third World Medicine, 4, 1.

[5] World Health Organization (WHO) (2002) The Prevention and Control of Schistosomiasis and Soil Transmitted Helminthiasis. WHO, Geneva.

[6] Raina, A., Yattoo, G.N., Wani, F.A., Para, R.A., Changal, K.A. and Parry, A.H. (2013) Pancreatitis Secondary to Ascaris lumbricoides: A Case Series Analysis. International Journal of Medicine Research and Health Sciences, 2, 673677. http://dx.doi.org/10.5958/j.2319-5886.2.3.053

[7] Brooker, S., Clements, A. and Bundy, D.A.P. (2006) Global Epidemiology, Ecology and Control of Soil Transmitted Helminth Infections. Advanced Parasitology, 62, 223-265. http://dx.doi.org/10.1016/S0065-308X(05)62007-6

[8] Uchenna, C.O., Nwora, A.O. and Samuel, A. (2005) Helminthiasis in Pregnancy in Enugu, Nigeria. Journal Health Sciences, 51, 291-293. http://dx.doi.org/10.1248/jhs.51.291

[9] Luka, S.A, Ajogi, I. and Umoh, J.U. (2000) Helminthiasis among School Children in Lere Local Government Area, Kaduna State, Nigeria. The Nigeria Journal of Parasitology, 21, 109-116.

[10] Cheesbrough, M. (2000) District Laboratory Practice in Tropical Countries, 3rd Edition, Part One, Cambridge University Press, Cambridge, 214-215.

[11] Dada, E.O. and Erinle, B.A. (2004) Study of Human Gastro-Intestinal Parasites among Primary School Children in Ibule Soro Community of Ifedore Local Government Area of Ondo State, Nigeria. Journal of Medical Laboratory Science, 13, 62-65.

[12] Cheesbrough, M. (2006) Parasitological Tests. In: Cheesbrough, M., Ed., District Laboratory Practice in Tropical Countries Part 1, 2nd Edition, Cambridge University Press, Cambridge, 184-201. http://dx.doi.org/10.1017/CBO9780511543470

[13] Biu, A.A. and Harry, J. (2001) Gastrointestinal Parasites: A Prevalence Study amongst School Children in Maiduguri, Nigeria. Bioscience Research Communications, 13, 609-613.

[14] Agwu, N.A. (2001) Incidence of Intestinal Helminthiasis in School Children in Aba Urban City, Abia State Nigeria. International Journal of Environmental Health and Human Development, 1, 47-51.

[15] Oninla, S.O., Owa, J.A., Onayade, A.A. and Taiwo, O. (2007) Intestinal Helminthiases among Rural and Urban Schoolchildren in South-Western Nigeria. Annals of Tropical Medicine \& Parasitology, 101, 705-713. http://dx.doi.org/10.1179/136485907X241406

[16] Willingham, A.L., Wu, H.W., Conlan, J. and Satrija, F. (2010) Combating Taenia solium Cysticercosis in Southeast Asia: An Opportunity for Improving Human Health and Livestock Production. Advances in Parasitology, 72, 235-266. http://dx.doi.org/10.1016/S0065-308X(10)72009-1

[17] Tedia, S. and Ayele, T. (1986) Ascaris lumbricoides Distribution in Ethiopia. Ethiopian Medicine Journal, 24, 79-86.

[18] Hotez, P.J. and Pritchard, D.I. (1995) Hookworm Infection. Scientific American, 272, 68-74. http://dx.doi.org/10.1038/scientificamerican0695-68

[19] Obiukwu, M.O., Umeanaeto, P.U., Eneanya, C.I. and Nworgu, G.O. (2008) Prevalence of Gastro-Intestinal Helminth in School Children in Mbaukwu, Anambra State, Nigeria. Annals of Tropical Medicine \& Parasitology, 101, 705-713. http://dx.doi.org/10.4314/njpar.v29i1.37897

[20] Uwem, F.E., Simon, N.O.E., Chiedu, F.M. and Sammy, O.S. (2008) Helminthiasis and Hygiene Conditions of Schools in Ikenne Ogun State, Nigeria. PLoS Neglected Tropical Diseases, 2, e146.

[21] Agi, P.I. (1997) Comparative Helminths Infections of Man in Two Rural Communities of the Niger Delta, Nigeria. West African Journal Medicine, 16, 232-238. 